\title{
Hospital Equipment Management System for a Poor Resource Setting
}

\author{
J. L. P. Chaminda \\ Registrar in Medical Administration, Ministry of Health, Sri Lanka. \\ DOI: 10.29322/IJSRP.11.01.2021.p10982 \\ http://dx.doi.org/10.29322/IJSRP.11.01.2021.p10982
}

\begin{abstract}
Hospital equipment management plays a vital role in ensuring of good healthcare service in the region or country which indicates the need of properly managed hospital equipment in healthcare setting. Healthcare staff including doctors, nurses or other supporting staff cannot perform well to provide good health, without having properly managed hospital equipment. Delivery of poor quality health service may be resulted with the absence of well-developed hospital equipment management system which can leads to disability or death sometimes. Development of hospital equipment management system using Japanese $5 \mathrm{~S}$ total quality management tool was propose with this paper. Although this is simple and cheaper method, can achieve dramatically significant change to healthcare system.
\end{abstract}

Index Terms- Equipment management, Healthcare service

\section{INTRODUCTION}

$\mathrm{M}$ anagement of hospital equipment is a cycle that starts with planning, procurement, acquisition, installation, commission, decommissioning and ends with disposal of hospital equipment [1]. The hospital equipment management (healthcare technology management) certifies that hospital equipment and other systems used in healthcare are safe, operational and a proper maintenance of the equipment. Medical Equipment \& Technology Association (META) defines the hospital equipment as part of the medical device which can be used for intended medical purposes in hospital care. Every hospital equipment needs a routine maintenance and services such as calibration, repair and decommissioning of them within the hospital.

The hospital equipment used for diagnosis, rehabilitation, monitoring and treatment of medical conditions which is typically managed by biomedical engineers with the support of technologists. The duties of the biomedical technologist or engineer serve as an interface between the equipment and health staff and in enabling that hospital equipment to keep in good working condition [2].

Governed policies and procedures give direction in selection, planning and acquisition of the hospital equipment which include procedures for the inspection, acceptance, maintenance, equipment breakdown and troubleshooting of the equipment and hospital equipment disposal [3]. The Association for the Advancement of Medical Instrumentation (AAMI) is named as one of well recognized organization working for advancing the development, safe and effective use of medical technology founded in 1965. Although the policies and guidance are available, inadequate implementation of them were seen. There should be a possible ways to overcome those in health sector. Recognized healthcare technology management ensures that medical equipment used in healthcare should be safe and in good operations. There should be a proper management of the hospital equipment to meet the safe and in good operations which results patient care.

Well-developed hospital equipment management contributes to countries socio-economic development by promoting good health of the people. Health sector would face numerous challenges in the absence of well managed healthcare technology management system. Implementation of $5 \mathrm{~S}$ quality management tool can be done with available resources in the health sector for medical equipment management system. Health administrators in various levels have a major role in designing and implementing of such uniform method in the health system.

There are various challenges met in managing the hospital equipment properly, mostly in the developing countries. Regional disparities also were seen in managing the hospital equipment in many of the countries. Most of the literature given the evidence of common challenges involved in hospital equipment management which can be listed as are the following:

- Poor knowledge of medical administrators on long term impact of hospital equipment maintenance and service.

- Poor financial capability on hospital equipment maintenance.

- Prolonged downtime of hospital equipment.

- Low priority on innovative ways of using the hospital equipment.

- Inability to provide technical trainings to equipment users.

- Lack of regular audits on hospital equipment use.

- Improper reporting system in relation to hospital equipment management.

- Unavailability of continuous supply of spare parts or accessories.

- Unavailability of evidence-based information system on health care technology.

Most of the challenges or failures stated above can be prevented by implementing Planned Preventive Maintenance (PPM) policies as recorded by the procurement process resource guide under WHO medical device technical series [4]. Use of hospital equipment continue without maintenance in rural hospitals probably in developing countries were seen. Hospital equipment gets wear out and deteriorate completely till those 
things are rectified. Other than the maintenance, the hospital equipment failures can be occur due to various other causes. They can be classified as improper storage and transportation, initial failure, inappropriate handling, inadequate maintenance, environmental stress, production deficiency, random failure, inappropriate repair technique, and wear-out failure [3,5].

The $5 \mathrm{~S}$ is an acronym of five Japanese words of Seiri, Seiton, Seiso, Seiketsu, and Shitsuke [6]. They can be listed simply as Sort, Set in Order, Shine, Standardize, and Sustain. The $5 \mathrm{~S}$ methods is a total quality management tool introduced by Japanese which used to organize the workplace in a clean, efficient and safe manner purposefully to enhance productivity and to ensure the level of standardized work [7]. This concept was used by various sectors to ensure total quality of work by keeping the institution in a better state. The managers in an organization has a major role to engage people with the use of principles and discipline to keep clean up their workplace. There are benefits following the implementation of the $5 \mathrm{~S}$ in the management of hospital equipment with the leadership of health managers [8].

- Performance improvement in productivity and quality

- To improved safety and equipment availability.

- Important to develop discipline to detect early for repair equipment.

- Important to develop a better discipline detect reduction of waste and cost.

- Improved employee morale.

- Employees including hospital managers to give sense of responsibility and ownership.

Introduction of concept of $5 \mathrm{~S}$ of the quality tool in production industries gained many benefits by various ways. Implementation of 5S quality improvement tool successfully by healthcare technologist or biomedical engineers for the proper management of the hospital equipment $[9,10]$. Introduction of $5 \mathrm{~S}$ tool for hospital equipment management can be mentioned as below.

\begin{tabular}{|l|l|}
\hline Sort & $\begin{array}{l}\text { Sorting of hospital equipment by removing } \\
\text { unnecessary equipment and disposing them } \\
\text { according to the circulars and guidelines. } \\
\text { Contacting of expertise prior to buying } \\
\text { equipment also important to avoid wastes. }\end{array}$ \\
\hline Set in order & $\begin{array}{l}\text { Prioritization of hospital equipment prior to } \\
\text { purchasing need to be done by medical } \\
\text { administration leaders with the help of relevant } \\
\text { stakeholders. Always important to buy hospital } \\
\text { equipment from trusted companies which have } \\
\text { the capacity to facilitate equipment } \\
\text { demonstration and staff trainings on time. }\end{array}$ \\
\hline Shine & $\begin{array}{l}\text { Cleaning and keeping hospital equipment dust } \\
\text { free will leads to increase lifespan of the } \\
\text { equipment. Regular inspection also have to be } \\
\text { done accordingly to identify potential } \\
\text { problems. }\end{array}$ \\
\hline Standardize & $\begin{array}{l}\text { Measuring of hospital equipment targeting the } \\
\text { standard and up to and are in good operations. } \\
\text { Checking of the functions before use and } \\
\text { establish a method to ensure consistent strategy } \\
\text { for successful 5S implementation. }\end{array}$ \\
\hline
\end{tabular}

\begin{tabular}{|l|l|}
\hline Sustain & $\begin{array}{l}\text { Strengthening of the system to sustain the } \\
\text { workflow always and never break the line is } \\
\text { very important. Health administrators in } \\
\text { various levels have a great role to measure the } \\
\text { performance on time. }\end{array}$ \\
\hline
\end{tabular}

\section{DisCUSSION}

Almost every hospital equipment is being imported generating an arena of numerous challenges faced by the health managers mainly in developing countries as well as rural areas. The absence of maintenance and repairs of hospital equipment, improper procurement plan, improper calibration, and poor validation of the equipment are the common problems in hospital equipment management. There can be a situation where there are insufficient education and operative training for both the hospital administrators and the equipment operators on the importance of routine hospital equipment maintenance. Inadequate knowledge on correct commission and decommission of hospital equipment and absence of timely proper disposal also considered as a challenges. Those challenges can be overcome by implementing of planned preventive maintenance and regulatory body for auditing of hospital equipment system with allotting sufficient budgetary support. Planned preventive maintenance itself prevent most of corrective maintenance which is cost saving and reduce service interruptions. General concept of $5 \mathrm{~S}$ can be used as a healthcare technology (hospital equipment) tool which is simple practical method to improve quality of work without using additional resources [11,12].

\section{CONCLUSION}

Main aim of health sector in any country to make the population healthy to contribute for national development. That can be achieved by promoting health through access to quality health to all people. The hospital equipment should be available always in the safe manner to provide the required service to their care seekers. On the other way health staff should be free from potential harm associated with hospital equipment used in healthcare. This can be achieved by implementing a proper hospital equipment management system in all hospitals without considering of size or location of the hospital. Hospital equipment management guarantees that hospital equipment and other related systems in healthcare are operational and safe to achieve the mission and vision of the healthcare. Sorting out, setting in order, make them clean, standardizing of health policies and to measures to sustain the good quality culture till quality healthcare delivery is attained can be done simply by implementing 5S. Support of medical administrators, biomedical engineers, biomedical technologists are vital to develop a quality management guideline in healthcare technology to improve standards and quality of hospital equipment management in health system.

\section{REFERENCES}

[1] Rajeev B., Ashish D. (2007) Healthcare knowledge management: Issues, advances, and successes. 
[2] Yadin D., Wolf W., von M., Michael R.N., Joseph D.B., et al. (2003) Clinical engineering (Principles and applications in engineering), CRC Press, USA.

[3] Khandpur R.S. (2004) Biomedical instrumentation: Technology and applications. Mc Graw hills, USA, p. 924.

[4] Zienaa, John (2009) Challenges of Medical Equipment Management in Ghana Health Service. CED, HASS, GHS.

[5] Dyro, Joseph (2004) Clinical engineering handbook (Biomedical engineering). (1st edn), Academic Press, USA, p. 696.

[6] Hirano, Hiroyuki (1995) Five pillars of the visual workplace. MA: productivity press, Cambridge, USA.

[7] Gapp R., Fisher R., Kobayashi K. (2008) Implementing 5S within a Japanese context: An integrated management system. Management decision 46(4): 565-579.

[8] Graban, Mark (2012) Lean hospitals: Improving quality, patient safety and employee engagement. Boca Raton, CRC Press, USA.
[9] Five S comprehensive education and resource center.

[10] World Health Organization (WHO) Medical device technical series (2011), Procurement process resource guide. WHO Press, Switzerland, Geneva.

[11] Reporting adverse incidents and disseminating medical device alerts, (2007). Medical Device Alert MDA/2007/01, January 2007.

[12] World Health Organization (WHO) global model regulatory framework for medical devices including IVDs, (2016).

\section{AUTHORS}

First Author - J. L. P. Chaminda, Registrar in Medical Administration, Ministry of Health, Sri Lanka.

Email: jlpchaminda@gmail.com 